\title{
Retinal blood flow after superior cervical ganglionectomy: a laser Doppler study in the cynomolgus monkey
}

\author{
M J Ménage, J C Robinson, P L Kaufman, W E Sponsel
}

\begin{abstract}
There is a conflicting literature regarding the possible presence of adrenergic innervation of the retinal circulation. The effect of a histologically confirmed left superior cervical ganglionectomy on the total retinal blood flow in eight anaesthetised female cynomolgus monkeys was determined. Near total unilateral ocular sympathetic denervation was confirmed by ipsilateral miosis, supersensitivity of pupillary dilatation to topical phenylephrine and pupillary hyporesponsiveness to topical hydroxyamphetamine. Retinal vein diameters were measured from monochromatic photographs, maximum red cell velocities $\left(V_{\max }\right)$ were measured with a helium-neon laser, using a bidirectional laser Doppler velocimeter technique, and the total retinal blood flow in each eye was determined by summation of measurements of flow in individual retinal veins. Mean (SEM) total retinal blood flow was 32.93 (1.49) and $30.41(1.86) \mu \mathrm{l} / \mathrm{min}$ in the eight sympathectomised and normal eyes respectively; the $9 \%$ (5\%) difference was not statistically significant. Our study suggests that pharmacologically confirmed sympathetic denervation has little if any effect on resting total retinal blood flow.

(BrF Ophthalmol 1994; 78: 49-53)
\end{abstract}

The possible presence of adrenergic innervation of the retinal vasculature is somewhat controversial. Based on standard neurohistological methods, sympathetic nerve fibres were originally believed to accompany the central retinal artery as it passes through the lamina cribrosa to innervate the arteriolar branches within the globe. ${ }^{1}$ However, a number of investigators; using a histofluorimetric technique for catecholamines, reported that the innervation to the central retinal artery did not extend beyond the lamina cribrosa in many species including rabbits, cats, and primates. ${ }^{2-4}$ Others have demonstrated unmyelinated nerve fibres with vesicles in the human retinal vessel adventitia ${ }^{56}$ and adrenergic nerve fibres in the wall of human and cynomolgus monkey retinal vessels beyond the lamina cribrosa. ${ }^{78}$ More recently, unmyelinated nerve fibres with nerve endings filled with vesicles have been described in the retinal arterioles of the rabbit.' These nerve endings disappeared following ipsilateral superior cervical ganglionectomy (SCGx).

The aim of this study was to investigate the effect of unilateral SCGx on the total retinal blood flow of the cynomolgus monkey using the non-invasive technique of bidirectional laser Doppler velocimetry (LDV).

\section{Materials and methods}

Eight young adult female cynomolgus monkeys (Macaca fascicularis) weighing $2 \cdot 0-2 \cdot 5 \mathrm{~kg}$ were studied. All procedures were in accordance with the ARVO Resolution on the Use of Animals in Research. All monkeys had a histologically confirmed left SCGx performed under a general anaesthetic, as previously described. ${ }^{10}$ Five monkeys underwent the surgery a mean of 31.8 months (range 30.1-33.2) before blood flow measurement, and three animals underwent the SCGx a mean of $2 \cdot 7$ months (range 2.6-2.9) before measurement. Substantial unilateral ocular sympathetic denervation was confirmed before and after blood flow measurements in all eight animals by ipsilateral miosis and supersensitivity of pupillary dilatation to topical $0 \cdot 1 \%$ phenylephrine, and marked hyporesponsiveness to topical $1 \%$ hydroxyamphetamine. The pupillary supersensitivity to phenylephrine was qualitatively similar in all eight animals, but the hyporesponsiveness to hydroxyamphetamine was slightly more pronounced in the three more recently ganglionectomised animals.

Anaesthesia for the blood flow measurements was a mixture of intramuscular ketamine $15 \mathrm{mg} / \mathrm{kg}$, xylazine $1 \mathrm{mg} / \mathrm{kg}$, and acepromazine $0.2 \mathrm{mg} / \mathrm{kg}$ supplemented by further doses as required to maintain total akinesia of the eye. Previous attempts using intramuscular or intravenous pentobarbitone had been unsuccessful due to an induced small amplitude nystagmus. The pupils were dilated with two or more drops of topical $1 \%$ cyclopentolate. Although phenylephrine might have enhanced the pupillary dilatation, it was avoided because of possible denervation supersensitivity of the retinal vasculature to an adrenergic agent.

In order to maintain the clearest possible view, a plano contact lens was placed on the sodium hyaluronate (Healon, Pharmacia Ophthalmics, Piscataway, NJ) covered cornea before LDV measurements and photography. Left and right 


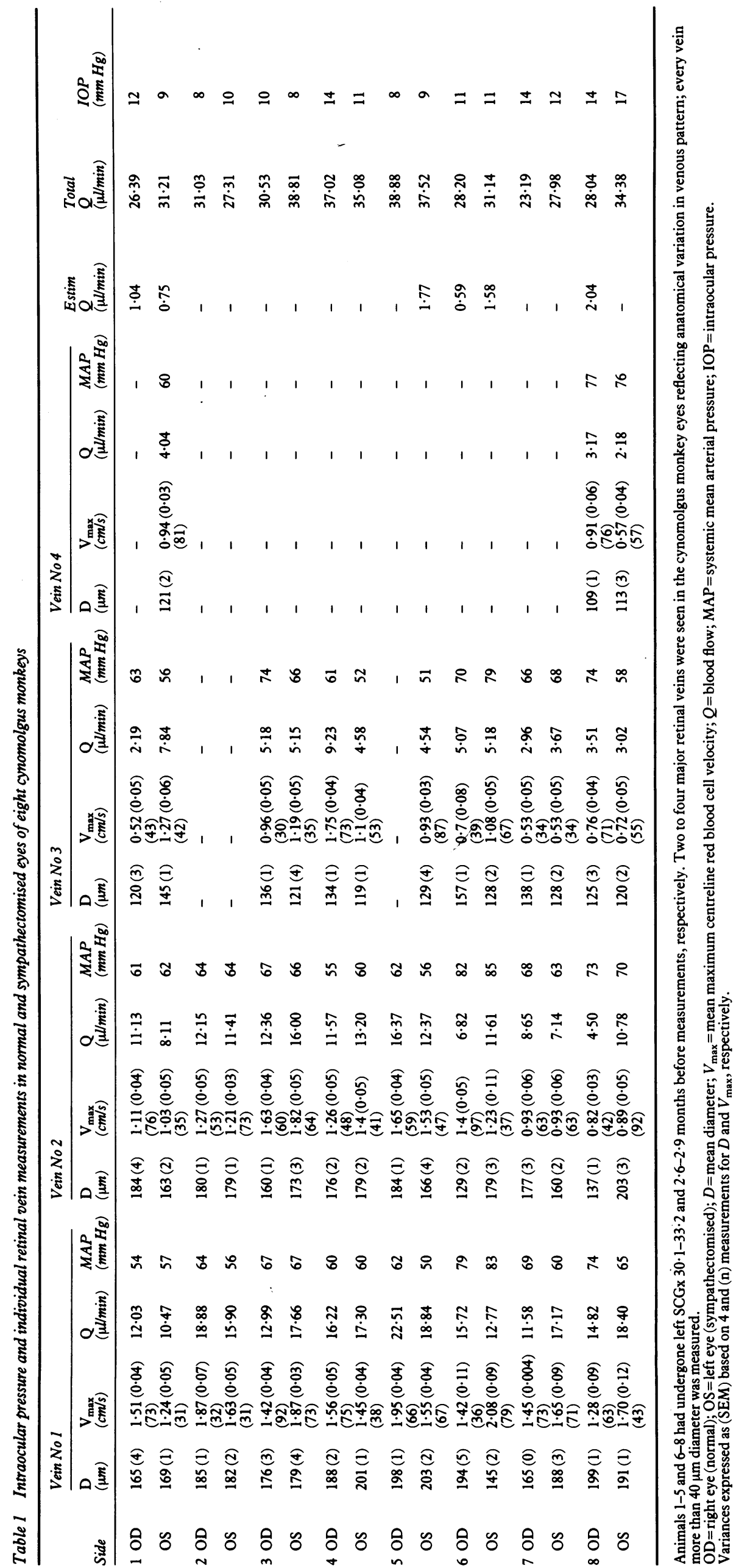


eyes were measured in random order. Mean systemic arterial blood pressure (MAP) was monitored throughout the experiments using a Dinamap monitor (Critikon Inc, Tampa, FL, USA) with a neonatal brachial cuff. Intraocular pressure (IOP) was measured with a minified Goldmann tonometer ${ }^{11}$ at the end of each experiment.

Maximum red cell velocities $\left(V_{\max }\right)$ in the retinal veins were measured with a helium-neon laser, using a bidirectional LDV technique. ${ }^{12}{ }^{13}$ For each vein, six 3 second segments, each consisting of 72 separate pairs of Doppler shift frequency spectra (DSFS) were recorded. Any unsatisfactory recordings (poor cut offs, poorly centred or drifting laser) were rejected at the time of measurement. Satisfactory recordings were stored and then analysed using a custom designed computer program. ${ }^{14}$ The computer calculates the cut off frequency of each DSFS and randomly presents each spectrum with a cut off line on the screen for rejection or acceptance by the observer. In this way the spectra with the most clear cut offs are selected without bias to calculate mean $V_{\max }$. A correction factor based on the mean axial length of the eye, measured by A-scan ultrasonography (17.68 (SEM 0.19) mm) was entered into the computer for calculation of $V_{\max }$. Since decentration of the laser will tend to decrease the value of $V_{\max }$, after analysis the accepted spectra from the three segments with the highest mean value were used to calculate an average $V_{\max }$ for each vein. In this way an average value of $V_{\max }$ was calculated from different numbers of measurements of $V_{\max }$, but always more than 30 , for each vein.

The LDV recordings were made at locations which provided the most distinct cut off frequencies when the laser beam was moved along the vessel. If possible, venous junctions or arteriovenous crossings were avoided. All locations of measurement were within 3 disc diameters of the disc margin and were marked on a colour fundus photograph for referencing diameter measurements. Throughout the recordings the fundus was diffusely illuminated with monochromatic light $(\lambda=570 \mathrm{~nm})$.

After measurements of $V_{\max }$ in both eyes, the fundi were photographed with a Zeiss fundus camera using Kodak Tmax 100 film through a $570 \mathrm{~nm}$ filter. Negatives were projected onto a screen and the diameter of the veins at the marked locations measured in a masked fashion with a calliper. A mean diameter for each vein was determined from one measurement from each of four negatives of each eye. Total magnification of the projected fundus image was $\times 113$. This includes an estimated eye-fundus camera magnification of $\times 2.35$ based on a mean refraction of dilated monkey eyes with plano contact lenses of $-2 \cdot 14(0 \cdot 47)$ dioptres.

A few eyes had a single retinal vein too narrow $(\leqslant 80 \mu \mathrm{m})$ to measure $V_{\max }$ accurately but wide enough $(\geqslant 40 \mu \mathrm{m})$ to measure the diameter. The flow in these veins was estimated from the total retinal blood flow by comparing the relative cross section of the vein against the total venous cross section in each eye. A few thread-like vessels (diameter $<\sim 20 \mu \mathrm{m}$ ) were seen in all eyes but were too narrow to accurately measure either diameter or $V_{\max }$, or indeed to identify as veins or arteries. The cross sectional area of these tiny vessels was likely to be comparable in the paired eyes and any difference in flow to be inconsequential.

Volumetric blood flow rate $(Q)$ of each vein was calculated as ${ }^{13}$

$$
Q=\frac{\pi D^{2}}{4} V_{\text {mean }}
$$

where $D$ is the mean vessel diameter and mean blood velocity $\left(V_{\text {mean }}\right)$ is calculated as

$$
V_{\text {mean }}=\frac{V_{\text {max }}}{1.6}
$$

These equations assume a circular cross section of the vessels and a proportionality constant of 1.6 between centreline red cell velocity and mean blood velocity. ${ }^{15-17}$

Total retinal blood flow of each eye was obtained by summing the blood flow in each of the veins.

The blood flow data for sympathectomised and contralateral control eyes were compared with a paired two tailed $t$ test.

\section{Results}

Measurements of venous diameter, $V_{\max }$, blood flow, MAP, and IOP are all summarised in Table 1. The number of major retinal veins varied from two to four in the monkey eyes. There was no significant difference in MAP measured during flow measurements (unpaired two tailed $t$ test), or IOP measured after experiments (paired two tailed $t$ test), in sympathectomised eyes compared to contralateral control eyes. There was no significant correlation between mean MAP measurement and total blood flow of each eye (Spearman). Vessel diameter and $V_{\max }$ were highly correlated (Spearman $\mathrm{p}<0.001$ ).

The total retinal blood flows and statistical analysis are summarised in Table 2 . For all eight animals collectively, and for the five animals sympathectomised 30 or more months previously, there was no significant difference in total retinal blood flow between sympathectomised and contralateral control eyes. In the three animals sympathectomised less than 3 months previously, blood flow averaged $18 \%$ higher in the sympathectomised eye than in the contralateral controls. This was not statistically significant by the Wilcoxon signed rank test.

Total retinal venous cross section calculated from venous diameters at the disc margin of each eye was not significantly different between sympathectomised and control eyes for all eight animals, the five long term animals or the three short term animals. This would indicate that there was no significant retinal venodilatation as a result of SCGx.

\section{Discussion}

Other investigators have reported the response of the retinal vasculature and retinal blood flow to removal or stimulation of the sympathetic innervation of the globe. Rabbit retinal vessels have been shown to vasodilate after bilateral SCGx. ${ }^{18}$ Using the radioactively labelled micro- 
Table 2 Total retinal blood flows and statistical analysis

\begin{tabular}{|c|c|c|c|c|c|}
\hline $\begin{array}{l}\text { Monkey } \\
\text { No }\end{array}$ & $\begin{array}{l}\text { Months after } \\
\text { SCGX }\end{array}$ & $\begin{array}{l}O D \text { (normal) } \\
(\mu l / \min )\end{array}$ & $\begin{array}{l}\text { OS } \\
(\mu \mathrm{sym} \min )\end{array}$ & $\underset{(\mu / / \min )}{O S-O D}$ & $O S / O D$ \\
\hline $\begin{array}{l}1 \\
2 \\
3 \\
4 \\
5 \\
6 \\
7 \\
8 \\
n=5(\operatorname{Nos} 1-5) \\
n=3(\operatorname{Nos} 6-8) \\
n=8\end{array}$ & $\begin{array}{c}30 \cdot 1 \\
30 \cdot 1 \\
33 \cdot 1 \\
32 \cdot 7 \\
33 \cdot 2 \\
2.9 \\
2.7 \\
2.6 \\
31 \cdot 8(0 \cdot 7) \\
2 \cdot 7(0 \cdot 1) \\
20.9(5 \cdot 3)\end{array}$ & $\begin{array}{l}26 \cdot 39 \\
31 \cdot 03 \\
20 \cdot 53 \\
37 \cdot 02 \\
38 \cdot 88 \\
28 \cdot 20 \\
23 \cdot 19 \\
28 \cdot 04 \\
32 \cdot 77(2 \cdot 21) \\
26 \cdot 48(1.64) \\
30 \cdot 41(1 \cdot 86)\end{array}$ & $\begin{array}{l}31 \cdot 21 \\
27 \cdot 31 \\
38 \cdot 81 \\
35 \cdot 08 \\
37 \cdot 52 \\
31 \cdot 14 \\
27 \cdot 98 \\
34 \cdot 38 \\
33.99(2 \cdot 11) \\
31 \cdot 17(1 \cdot 85) \\
32 \cdot 93(1 \cdot 49)\end{array}$ & $\begin{array}{r}4.82 \\
-3.72 \\
8.28 \\
-1.94 \\
-1.36 \\
2.94 \\
4.79 \\
6.34 \\
1.22(2.24)^{\star} \\
4.69(0.98) \dagger \\
2.45(1.52)^{\star}\end{array}$ & $\begin{array}{l}1.18 \\
0.88 \\
1.27 \\
0.95 \\
0.97 \\
1.10 \\
1.21 \\
1.23 \\
1.05(0.07)^{\star} \\
1.18(0.04)+ \\
1.09(0.05)^{\star}\end{array}$ \\
\hline
\end{tabular}

$\mathrm{OD}=$ right eye; $\mathrm{OS}=$ left eye; $\mathrm{SCG}$ = left superior cervical ganglionectomy

Grouped data are mean (SEM) for $\mathrm{n}$ animals.

$\star$ Not significant by the paired two tailed $t$ test.

tNot significant by the Wilcoxon signed rank test $(n=3)$.

sphere method of measuring flow, Weiter et $a l^{19}$ reported a $32 \%$ increase in feline retinal blood flow after SCGx and a $41 \%$ decrease after sympathetic stimulation. It has been suggested that the marked effect shown in this study using $50 \mu \mathrm{m}$ spheres, in contrast to studies using smaller spheres, ${ }^{20}$ could be due to extraocular vasoconstriction trapping the spheres and reducing the estimate of retinal blood flow. ${ }^{21}$

Using close retinal oxygen tension as an indicator for flow changes, $\mathrm{Alm}^{22}$ was unable to demonstrate any effect of close arterial injection of noradrenaline on the retinal arterioles. However, sympathetic denervation supersensitivity has been shown after SCGx using radioactively labelled microspheres, with low doses of topical adrenergic agents causing a marked decrease in rabbit retinal blood flow. ${ }^{23} \mathrm{~A}$ decrease in the close retinal oxygen tension has been demonstrated after sympathetic stimulation in cats. ${ }^{20}$

Human retinal vessels will vasoconstrict in response to systemic sympathetic stimulation produced by sustained isometric contraction of the hand. ${ }^{24}$ This effect is diminished in diabetics with autonomic neuropathy, ${ }^{25}$ and in eyes with ipsilateral disruption of the cervical sympathetic tract (Horner's syndrome). ${ }^{26}$

We were unable to demonstrate any statistically significant difference between the retinal blood flow of sympathectomised and contralateral control eyes in the eight cynomolgus monkeys. The standard deviation (SD) of the difference in blood flow between the sympathectomised and control eyes was $4.35 \mu \mathrm{l} / \mathrm{min}$. Using a paired $t$ test with a significance level $\alpha=$ 0.05 our study of eight animals would have detected a difference in blood flow between the sympathectomised and control eyes of $5.5 \mu \mathrm{l} /$ min (18\%) with $86 \%$ power, and $6.0 \mu \mathrm{l} / \mathrm{min}$ (20\%) with $91 \%$ power.

Our mean value of 30.4 (SD 5.3) $\mu \mathrm{l} / \mathrm{min}$ for the normal cynomolgus eyes is comparable to previously reported values of 34 (SD 6.3) $\mu \mathrm{l} / \mathrm{min}$ obtained from normal human eyes also using the bidirectional laser Doppler technique to measure flow in individual retinal veins. ${ }^{13}$ Using the microsphere technique other investigators have reported macaque monkey blood flows of 25 (SD 9) $\mu \mathrm{l} / \mathrm{min}^{27}$ and 34 (SD 8) $\mu \mathrm{l} / \mathrm{min}^{28}$

We did not measure vessel diameters in synchronous phases of the cardiac cycle, as we were making venous flow measurements which would vary much less than retinal arterioles. There is probably a small variation in venous diameter which could affect the blood flow measurements. However, we used four separate fundal photographs for our vessel diameter measurements with an overall mean coefficient of variation of $3 \%$.

We found that xylazine was crucial in our intramuscular anaesthetic to maintain the absolute akinesia necessary for accurate laser Doppler measurements. Xylazine is related to clonidine and could possibly have decreased the central sympathetic tone and/or affected peripheral $\alpha$ adrenergic receptors of the monkeys. This may have minimised the difference in blood flow between eyes. Conversely ketamine elevates sympathetic tone and could theoretically increase the difference between sympathectomised and control eyes. ${ }^{29} 30$

There was some variation in the MAP during flow measurements performed on vessels of the same eye. This may have been partially due to the inaccuracy of MAP measurement in the cynomolgus monkey using a neonatal brachial cuff and partially due to variation induced by a complex anaesthetic cocktail which required supplemental dosing during experiments.

In conclusion, the present study does not show any substantial effect of SCGx on the total retinal blood flow of the resting cynomolgus monkey. It may be that the sympathetic innervation of the eye is of more importance during episodes of stress such as systemic hyper or hypotension, hypoxia, or hypercapnia. There was also a tendency for the most recently denervated animals to show a difference in retinal blood flow between the two eyes. Some adaptation of the circulation to sympathetic denervation may occur with time. Further studies of the effect of sympathetic stimulation and denervation during induced conditions of circulatory stress, particularly at an early post-denervation stage, and of adrenergic agonists and antagonists, on retinal blood flow are indicated.

Supported by the NIH (EY02698 and EY06254), the Merck Foundation, the Hamilton Roddis Foundation. MJM supported in part by Bristol and Weston Health Authority and the Ethicon Awards of the College of Ophthalmologists.

1 Duke-Elder S, Wybar $K$. The anatomy of the visual system. In: System of ophthalmology. London: Kimpton, 1961: 853 .

2 Laties AM, Jacobowitz D. A comparative study of the autonomic innervation of the eye in monkey, cat, and rabbit. Anat Rec 1966; 156: 383-96.

3 Malmfors T. The adrenergic innervation of the eye as demonstrated by fluorescence microscopy. Acta Physiol Scand 1965; 65: 259-67.

4 Laties AM. Central retinal artery innervation. Arch Ophthalmol 1967; 77: 405-9.

5 Nomura T. Fine structure of the human retinal arteriole: a sphincter like structure in the side arm branching and unmyelinated nerve fibres. in the adventitia. $\mathscr{f} p n \mathcal{F}$ Ophthalmol 1972; 16: 158-66.

6 Fuduka M. Presence of adrenergic innervation to the retinal vessels: a histochemical study. Fpn $\mathcal{F}$ Ophthalmol 1970; 14:
91-7.

7 Ruskell GL. Dual innervation of the central retinal artery of the retina in monkeys. In: Kants JS, ed. The optic nerve. London: Kimpton, 1972: 45.

8 Ehinger B. Adrenergic nerves to the eye and to related structures in man and in the cynomolgus monkey. Invest structures in man and in the cynomo
Ophthalmol Vis Sci 1966; 55: 42-52.

9 Furukawa $\mathrm{H}$. Autonomic innervation of pre-retinal blood vessels of the rabbit. Invest Ophthalmol Vis Sci 1987; 28: 1752-60.

10 Robinson JC, Kaufman PL. Superior cervical ganglionectomy in monkeys: surgical technique. Invest Ophthalmol Vis $S c i$ 1992; 33: 247-51

11 Kaufman PL, Davis GE. 'Minified' Goldmann applanating prism for tonometry in monkeys and humans. Arch Ophthalmol 1980; 98: 542-6. 
12 Riva CE, Grunwald JE, Sinclair SH, O’Keefe $\mathrm{K}$. Fundus camera based retinal LDV. Appl Optics 1981; 20: 117-20.

13 Riva CE, Grunwald JE, Sinclair SH, Petrig BL. Blood velocity and volumetric flow rate in human retinal vessels. Invest Ophthalmol Vis Sci 1985; 26: 1124-32.

14 Petrig BL, Riva CE, Grunwald JE. Computer analysis of laser Doppler measurements in retinal blood vessels. ARVO Abstracts. Invest Ophthalmol Vis Sci 1984; 25 (suppl): 7.

15 Baker $M$, Wayland $\mathbf{H}$. On-line volume flow rate and velocity profile measurements for blood in microvessels. Microvasc Res 1974; 7: 131-43.

16 Lipowsky HH, Zweifach BW. Application to the 'two slit' photometric technique to the measurement of microvascular volumetric flow rates. Microvasc Res 1978; 15: 93-101.

17 Damon DN, Duling BR. A comparison between mean blood velocities and centre-line red cell velocities as measured with a mechanical image streaking velocimeter. Microoasc Res 1979; 17: 330-2.

18 Seitz $R$. Zur vegetativen innervation von pupille und netzhautgefaßen. Ber Dtsch Ophthalmol Ges 1953; 58: 55-61.

19 Weiter JJ, Schachar RA, Ernest JT. Control of intraocular blood flow. II Effects of sympathetic tone. Invest Ophthalmol Vis Sci 1973; 12: 332-47.

$20 \mathrm{Alm} \mathrm{A}$, Bill A. The effect of stimulation of the cervical sympathetic chain on retinal oxygen tension and on uveal, retinal and cerebral blood flow in cats. Acta Physiol Scand 1973; 88: 84-94.

21 Bill A. Blood circulation and fluid dynamics in the eye. Physiol Rev 1975; 55: 383-417.

22 Alm A. Effects of norepinephrine, angiotensin, dihydroergotamine, papaverine, isoproterenol, histamine, nicotinic acid, and xanthinol nicotinate on retinal oxygen tension in cats. Acta Ophthalmol 1972; 50: 707-19.

23 Morgan TR, Green K, Bowman K. Effects of adrenergic agonists upon regional ocular blood flow in normal and ganglionectomized rabbits. Exp Eye Res 1981; 32: 691-7.

24 Lanigan LP, Clark CV, Hill DW. Retinal circulation responses to systemic autonomic nerve stimulation. Eye 1988; $2: 412-7$.

25 Lanigan LP, Clark CV, Allawi J, Hill DW, Keen H. Responses of the retinal circulation to systemic autonomic
nerve stimulation in diabetes mellitus. Eye 1989; 3: 39-47.

26 Lanigan LP, Birche R, Clark CV, Hill DW. The effect of cervical sympathectomy on retinal vessel responses to systemic autonomic nerve stimulation. Eye 1990; 4: 181-9.

27 Alm A, Bill A. Ocular and optic nerve blood flow at normal and increased intraocular pressure in monkeys (Macaca irus): a study with radioactively labelled microspheres including flow determinations in brain and some other tissues. Exp Eye Res 1973; 15: 15-29.

28 Alm A, Bill A, Young FA. The effect of pilocarpine and neostigmine on the blood flow through the anterior uvea in monkeys: a study with radioactively labelled microspheres. Exp Eye Res 1973; 15: 31-6.

29 Nedergaard OA. Cocaine-like effect of ketamine on vascular adrenergic neurones. Eur $\mathcal{f}$ Pharmacol 1973; 23: 153-61.

30 Koehntop DE, Liao J-C, van Bergen FH. Effects of pharmacologic alterations of adrenergic mechanisms by cocaine, tropolone, aminophylline and ketamine on epinephrineinduced arrhythmias during halothane-nitrous oxide anesthesia. Anesthesiology 1977; 46: 83-93. 